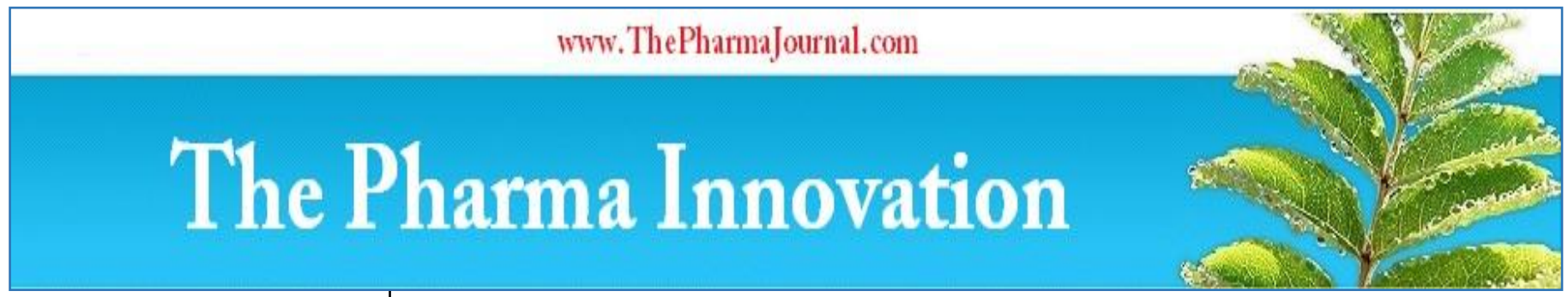

ISSN (E): $2277-7695$

ISSN (P): 2349-8242

NAAS Rating: 5.03

TPI 2021; 10(1): 735-738

(C) 2021 TPI

www.thepharmajournal.com

Received: 28-11-2020

Accepted: 30-12-2020

\section{Dr. Pooja}

Department of Apparel and

Textile Science, College of

Community Science, Punjab

Agricultural University,

Ludhiana, Punjab, India

\section{Dr. Sandeep Bains}

Department of Apparel and

Textile Science, College of

Community Science, Punjab

Agricultural University,

Ludhiana, Punjab, India

\section{Dr. Pritpal Singh}

Department of Plant Breeding

and Genetics, Punjab

Agricultural University,

Ludhiana, Punjab, India

\section{Evaluation of mechanical properties of oak tasar silk waste/viscose blended knitted fabrics}

\author{
Dr. Pooja, Dr. Sandeep Bains and Dr. Pritpal Singh
}

DOI: https://doi.org/10.22271/tpi.2021.v10.i1j.5618

\begin{abstract}
The present study was carried out to investigate the effects of blending oak tasar silk waste with viscose fibre to develop blended yarns for the construction of high quality knitted fabrics. The oak tasar silk waste and viscose blended yarn were prepared on worsted spinning system with three different blend ratios viz. 60:40, 50:50 and 40:60, spun into two different yarn counts (15 Nm and $20 \mathrm{Nm})$ for each blend ratio. Best four yarns out of total six were selected for further development of Single jersey knitted fabrics using circular knitting machine. The prepared knitted fabrics were evaluated for mechanical properties: breaking load and elongation, bursting strength, fabric growth, fabric stretch, abrasion resistance, snag resistance and thermal insulation. Results revealed that the addition of viscose fibre content improved the bursting strength, elongation percentage, abrasion resistance and snag resistance.
\end{abstract}

Keywords: blending, knitted fabrics, mechanical properties, oak tasar waste, viscose

\section{Introduction}

Blending of different fibers is extensively practiced for uplifting the performance and the aesthetic properties of resultant fabric. Blending of natural fibers with man-made ones can provide the benefits of combining the good properties of both fiber components, such as comfort, softness, strength etc. These advantages also allow an increased variety of products to be made and deliver a stronger marketing advantage (Svetnickienė V and Ciukas R, 2009) ${ }^{[1]}$. Reckoning of the performance of blended yarns has also been studied by numerous authors (Pan N, Postle R, 1995; Pan N, Chen K, Monego CJ, Backer S, 2000 and Kemp A, Owen JD, 1995) ${ }^{[2,3,4]}$ Natural fibers and their blends with man-made fibers improve the performance characteristics. Natural fibres like silk, provide aesthetic comfort, synthetic fibres are easy to care and possess good strength properties, So blending with such a combination of fibres produces a fabric which is economical and also aesthetically appealing. The trend of blended fabrics have been increased even in India. Blending combines the attributes of each of the fibre and produces a proved state of blended fabric. While blending, the good qualities of the fibres are emphasized and poor ones are minimized, if mixing of fibres is done carefully. Hence, blending needs knowledge of both, fibre science and as well as art. It enables the technicians to produce a preffered fabric for desired enduse.

Blending of silk and viscose is advantageous over blending of silk and cotton. Viscose is more functional and uniform as compared to cotton, as it is a manmade fibre. It secures over synthetics, due to its biodegradable nature and thus causes fewer burden to ecosystem. Viscose exhibits a silk like aesthetics, drape and feel; and retains rich brilliant colour. Also viscose fibre is manufactured from cellulosic base which contributes many properties to it, that are similar to cotton and other natural cellulosic fibres.

Generally the yarn produced by blending is converted into fabric by the process of weaving. Very few attempts have been made to knit the blended yarns especially silk and viscose, therefore, in the present study efforts have been made to build a fabric with the help of knitting technology. Knitted fabrics have various advantages over woven ones. Knitted fabrics are produced by set of connected loops from a series of yarns. In this method one set of yarn is used and it does not require sizing. Yarn preparation is not necessary before fabric manufacturing and production capacity is more as compared to weaving. Also production cost is less than weaving cost and above $52 \%$ fabrics are produced by knitting technology in textile sector. Therefore, the present study was carried out to figure out the effects of blending oak tasar silk waste with viscose fibre to develop blended yarns for the construction of high quality knitted fabrics.

\footnotetext{
Corresponding Author: Dr. Pooja

Department of Apparel and Textile Science, College of Community Science, Punjab Agricultural University, Ludhiana, Punjab, India
}

735 


\section{Material and Methods}

Oak tasar silk waste and viscose blended yarns in three different proportions, viz. 60\% OTW: $40 \%$ V, 50\% OTW: $50 \% \mathrm{~V}$ and $40 \%$ OTW : $60 \% \mathrm{~V}$ were developed, using two different yarn counts $(15 \mathrm{Nm}$ and $20 \mathrm{Nm})$ for each blend ; maintaining yarn twist constant at the rate of 10 twists per inch for both the yarn counts. Hence six blended yarns were obtained from three blend ratios. Each blend ratio produced two type of yarns having different counts. Oak tasar silk waste was opened properly by hand and then was fed into carding machine. Further to this, the fibres were blended using gillbox. At this step, fibres were blended into different proportions. After this, drawing procedure was carried out. The developed yarn cones weighed $50 \mathrm{~g}$ each. Prepared yarns were tested for yarn eveness, yarn strength and moisture regain.

On the basis of the yarn properties evaluated in table 1, best four yarns were selected and further used to develop knitted fabrics using circular knitting machine. Single jersey knitted fabrics were developed by using suitable blended yarns viz. 60\% OTW:40\%V (20 Nm), 50\%OTW:50\%V (15 Nm) and both the counts of $40 \% \mathrm{OTW}: 60 \% \mathrm{~V}$ on knitting maching of gauge 10 using creel with 36 cones. Blended knitted fabrics were subject to mechanical properties listed in Table- 3 along with test method. Developed knitted fabrics were assigned codes for ease of discussion and understanding as mentioned in Table 2.

Table 1: Properties of blended yarns

\begin{tabular}{|c|c|c|c|c|c|c|}
\hline Yarn composition & Yarn count (Nm) & TPI & Breaking Force (g) & Moisture Regain (\%) & Neps (+200) & Yarn evenness (U\%) \\
\hline \multirow{2}{*}{ 60OTW\%: 40\%viscose } & 15 & 10 & 703.1 & 6.36 & 3155 & 21.84 \\
\cline { 2 - 7 } & 20 & 10 & 975.9 & 9.99 & 1915 & 23.4 \\
\hline \multirow{2}{*}{ 50OTW\%: 50\%viscose } & 15 & 10 & 794.1 & 8.36 & 2458 & 21.66 \\
\cline { 2 - 7 } & 20 & 10 & 699.9 & 7.98 & 2652 & 22.42 \\
\hline \multirow{2}{*}{ 40\%OTW: 60\%viscose } & 15 & 10 & 960.4 & 8.89 & 1877 & 19.43 \\
\cline { 2 - 7 } & 20 & 10 & 665.2 & 7.50 & 1447 & 19.54 \\
\hline
\end{tabular}

Table 2: Developed fabrics with codes

\begin{tabular}{|c|c|c|c|}
\hline Fabric code & Fibre Content & Yarn count (Nm) & Yarn Density (WPIxCPI) \\
\hline S1 & 60OTW\%: $40 \%$ viscose & 20 & $20 \times 16$ \\
\hline S2 & 50OTW\%: $50 \%$ viscose & 15 & $20 \times 15$ \\
\hline S3 & $40 \%$ OTW: $60 \%$ viscose & 15 & $20 \times 15$ \\
\hline S4 & $40 \%$ OTW: $60 \%$ viscose & 20 & $20 \times 16$ \\
\hline
\end{tabular}

CPI- Courses per inch, WPI- Wales per inch

Table 3: Fabric testing methods and equipments

\begin{tabular}{|c|c|c|}
\hline \multicolumn{2}{|c|}{ Fabric testing equipments } & Name of the equipment \\
\hline \multicolumn{2}{|c|}{ Test } & BS 5441:1988 \\
\hline Courses and wales per unit length & Textile inspector & IS 1966-78 Re 2006 \\
\hline Bursting strength & Diaphragm bursting & ASTM D 6614:07 \\
\hline $\begin{array}{c}\text { Elastic properties } \\
\text {-Fabric stretch } \\
\text {-Fabric growth } \\
\text {-Fabric recovery }\end{array}$ & Stretch recovery tester \\
\hline Flat abrasion resistance & & IS: 12673: 1989 \\
\hline Fabric pilling & Martindale abrasion tester & IS: 10971-1984 \\
\hline Snagging resistance & Digital pilling tester & BIS: 4303-1968 \\
\hline Tensile strength and elongation & ICI Mace snag tester & KES-F 7 THERMO LABO II \\
\hline Thermal Insulation & Tensile strength tester & Thermal Insulation Tester \\
\hline
\end{tabular}

\section{Results and Discussion}

Mechanical properties of developed blended fabrics have been presented in table 4

Table 4: Mechanical properties of blended fabric

\begin{tabular}{|c|c|c|c|c|c|c|}
\hline Mechanical parameters & $\begin{array}{c}\text { S } 1 \text { 60OTW:40viscose } \\
(20 \mathrm{Nm})\end{array}$ & $\begin{array}{c}\text { S } 2 \text { 50OTW:50viscose } \\
(15 \mathrm{Nm})\end{array}$ & $\begin{array}{c}\text { S 3 40OTW:60viscose } \\
(15 \mathrm{Nm})\end{array}$ & $\begin{array}{c}\text { S } 4 \text { 40OTW:60viscose } \\
(20 \mathrm{Nm})\end{array}$ & CV & CD \\
\hline \multicolumn{7}{|l|}{ Breaking load $(\mathrm{N})$} \\
\hline Waleswise & $177.57 \pm 2.994$ & $122.28 \pm 0.567$ & $175.85 \pm 2.884$ & $131.71 \pm 4.228$ & 0.191 & $29.095^{*}$ \\
\hline Coursewise & $136.51 \pm 3.227$ & $102.13 \pm 2.052$ & $158.55 \pm 2.904$ & $101.37 \pm 2.352$ & 0.224 & 15.493 \\
\hline \multicolumn{7}{|l|}{ Elongation (\%) } \\
\hline Waleswise & $44.53 \pm 0.357$ & $45.38 \pm 0.348$ & $49.24 \pm 0.518$ & $45.73 \pm 0.431$ & 0.045 & 5.059 \\
\hline Coursewise & $103.58 \pm 2.253$ & $103.44 \pm 2.155$ & $94.89 \pm 2.052$ & $111.89 \pm 2.957$ & 0.067 & 10.948 \\
\hline Bursting strength & $4.11 \pm 0.0565$ & $4.88 \pm 0.048$ & $4.90 \pm 0.005$ & $5.61 \pm 0.082$ & 0.126 & $0.18^{*}$ \\
\hline \multicolumn{7}{|c|}{ Elastic properties } \\
\hline -Fabric stretch (\%) & & & & & & \\
\hline Waleswise & $47.2 \pm 1.207$ & $46.16 \pm 0.440$ & $44.93 \pm 0.515$ & $45.3 \pm 0.993$ & 0.022 & 2.78 \\
\hline Coursewise & $128 \pm 0.134$ & $116.8 \pm 1.275$ & $112.8 \pm 1.701$ & $101.3 \pm 1.264$ & 0.096 & $4.04^{*}$ \\
\hline -Fabric growth $(\%)$ & & & & & & \\
\hline
\end{tabular}




\begin{tabular}{|c|c|c|c|c|c|c|c|}
\hline Waleswise & $10.13 \pm 0.257$ & $8.66 \pm 0.185$ & $10.0 \pm 0.161$ & $7.06 \pm 0$ & 0.160 & $0.58^{*}$ \\
\hline Coursewise & $34.90 \pm 0.672$ & $24.67 \pm 0.282$ & $19.60 \pm 0.224$ & $22.130 \pm 0.38$ & 0.265 & $1.39^{*}$ \\
\hline Flat abrasion resistance & $2500 \pm 14.977$ & $2000 \pm 39.552$ & $2200 \pm 35.388$ & $2500 \pm 28.583$ & 0.107 & $101.11^{*}$ \\
\hline \multicolumn{7}{|c|}{ Snagging resistance } \\
\hline Waleswise & $3.0 \pm 0.289$ & $3.5 \pm 0.289$ & $3.5 \pm 0.289$ & $3.0 \pm 0.289$ & 0.089 & $0.94^{*}$ \\
\hline Coursewise & $3.0 \pm 0.289$ & $3.5 \pm 0.289$ & $3.5 \pm 0.289$ & $3.0 \pm 0.289$ & 0.074 & $0.94^{*}$ \\
\hline Thermal insulation & & & & & \\
\hline Heat keeping ratio (\%) & $20.91 \pm 0.009$ & $15.20 \pm 0.237$ & $16.93 \pm 0.343$ & $14.78 \pm 0.323$ & 0.165 & $0.86^{*}$ \\
\hline Tog value & $1.54 \pm 0.032$ & $1.42 \pm 0.027$ & $1.46 \pm 0.015$ & $1.42 \pm 0.005$ & 0.039 & $0.07^{*}$ \\
\hline
\end{tabular}

\section{Breaking force (N)}

Table 4elicits that, the breaking force of fabric S1 was highest (177.57) in wales wise direction whereas, in course wise direction it was highest for fabric S3. Lowest breaking force was observed for fabric S2 (122.28) in wales wise direction and fabric $\mathrm{S} 4$ in course wise direction. The results of the breaking force of fabric were in accordance with the results of breaking force of blended yarns. Further the difference between all the fabric samples was significant in wales wise direction except for fabrics $\mathrm{S} 1$ and $\mathrm{S} 3$; and $\mathrm{S} 2$ and $\mathrm{S} 4$, whereas in course wise direction, the difference between all the fabric samples was non-significant, except for fabrics S2 and S4.

\section{Elongation (\%)}

It can be envisaged that, the elongation percent of fabric S3 was found to be highest (49.24) in wales wise direction whereas, in course wise direction, fabric S4 exhibited highest (111.89) elongation percentage. Second highest elongation was observed by fabric S4 (45.73) in wales wise direction and fabric S1 in course wise direction. Lowest elongation percent was depicted by fabric S1 in wales wise direction and fabric $\mathrm{S} 2$ in course wise direction. However, there was no significant difference between all the fabric samples in both the directions.

\section{Bursting strength}

Bursting strength is a method of measuring strength in which the material is stressed in all the directions at the same time and is therefore more suitable for materials such as knitted fabrics, lace or non-woven. The bursting strength of fabric S4 was highest with mean value of $5.61 \pm 0.082$, followed by

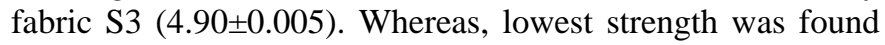
in fabric sample S1. Results clearly reveal that, as the proportion of viscose fibres in the yarn increases, the bursting strength also increase. Also there was a significant difference among all the fabric samples except for S2 and S3.

\section{Elastic properties}

The term elasticity describes the ability of a fabric to elongate (or stretch) when tension is applied, and to recover its original shape when the tension is released.

Fabric stretch: Highest fabric stretch per centage was found in fabric S1 in both wales wise and coarse wise direction with mean values of $47.2 \pm 1.207$ and $128 \pm 0.134$ respectively. Second highest fabric stretch was found in fabric S2 with mean values of $46.16 \pm 0.440$ in wales wise and $116.8 \pm 1.275$ in coarse wise direction, whereas, lowest stretch was reported in fabric S3 $(44.93 \pm 0.515)$ in wales wise and S4 (101.3 \pm $1.264)$ in coarse wise direction. Statistical analysis revealed that, there was no significant difference between all the fabric samples in wales wise direction, whereas, there was a significant difference between fabric samples in coarse wise direction except for fabrics S2 and S3.
Fabric growth: Maximum fabric growth was found in fabric $\mathrm{S} 1$ in both the directions with mean values as $10.13 \pm 0.257$ (wales wise) and $34.90 \pm 0.672$ (coarse wise). This was followed by fabric $\mathrm{S} 1$, second highest fabric growth was reported in fabric S3 in wales wise $(10.0 \pm 0.161)$ and fabric $\mathrm{S} 2$ in coarse wise $(24.67 \pm 0.282)$ direction. Minimum fabric growth was found in fabrics S4 and S3 in wales wise (7.06 \pm $0)$ and coarse wise $(19.60 \pm 0.224)$ direction respectively. Statistical data also revealed that, there was a significant difference among all the fabric samples in both the directions except for fabrics S1 and S3 in wales wise direction.

\section{Flat abrasion resistance}

Abrasion is an aspect of wear. It is the rubbing away of the component fibres and yarns of the fabric. The ability of a material to resist the action of abrasive forces is one of the major criteria to take into account for assessing the durability. Highest abrasion resistance was found same for both the fabrics S1 and S4 (2500 cycles), whereas, lowest resistance was noticed in fabric sample S2 with mean value of 2000 cycles. Statistically there was no significant difference between fabrics $\mathrm{S} 1$ and $\mathrm{S} 4$ but there was a significant difference among all the other fabric samples.

\section{Snag resistance}

Snagging is a defect caused by the pulling or plucking of yarns from a fabric surface. The degree of fabric snagging is assessed by comparing the tested specimens with visual standards. These visual standards could be either fabrics or photographs of fabrics. In this test standard photographs of fabrics were used to evaluate the snag resistance of fabrics. Photographic rating standards show the following extent of snagging:

\section{Rating 5 no snagging \\ Rating 4 slight snagging \\ Rating 3 moderate snagging \\ Rating 2 severe snagging \\ Rating 1 very severe snagging}

Results depicts that, a moderate snagging was found in fabrics S 1 and S4 with rating 3, whereas, there was a moderate to slight snagging in fabrics S2 and S3 with rating 3.5 in both wales wise and coarse wise ways. Further, it was analyzed that there was no significant difference among all the fabric samples in both the directions.

\section{Thermal insulation}

The effectiveness of a fabric as a thermal insulator depends upon its ability to hold as large an amount of still air as possible and then to retain this during use. Fabric S1 exhibited maximum heat keeping ratio $(20.91 \pm 0.009)$, followed, by fabric S3 (16.93 \pm 0.343$)$, whereas minimum thermal insulation was noticed in fabric S4 with mean value of 14.78 \pm 0.323 . Statistically the results were significant at 0.5 level 
of significance, except for, fabrics S2 and S4.

TOG value: TOG is a unit of measure of thermal insulation used in the textile trade and is the international standard measurement of a blanket's thermal effectiveness. Results for Tog value shows that highest tog value was found in fabric S1 $(1.54 \pm 0.032)$, followed, by fabric S3 (1.46 \pm 0.015$)$ and lowest value was observed in fabrics S2 and S4 with same mean value i.e. 1.42. Further, there was no significant difference observed between fabrics S2, S3 and S4.

\section{Conclusion}

Thus, it can be concluded that, blending of viscose fibre with oak tasar waste improves improved the bursting strength, elongation percentage, abrasion resistance and snag resistance of the resultant fabric. Therefore, blending of tasar silk waste with viscose offers an excellent scope, considering the overall characterictics of yarns and fabrics.

\section{Acknowledgement}

The authors are grateful to staff members of M.S. Randhawa library, Punjab Agricultural University, Ludhiana, for their co-operation in successful completion of the work. This work was part of the $\mathrm{PhD}$ study for first author and financed by University Grant Commission, New Delhi, India, through National Fellowship for OBC JRF.

\section{References}

1. Svetnickienè V, Ciukas R. Investigation of friction properties of yarns from natural fibers. Materials Science 2009;75(1):73-76.

2. Pan N, Postle R. Strengths of twisted blend fibrous structures: theoretical prediction of the hybrid effects. The Journal of the Textile Institute 1995;86(4):559-580.

3. Pan N, Chen K, Monego CJ, Backer S. Studying the mechanical properties of blended fibrous structures using a simple model. Textile Research Journal 2000;70(6):502-507.

4. Kemp A, Owen JD. The strength and behavior of nylon/cotton blended yarns undergoing strain. Journal of the Textile Institute 1995;46(11):T684-T698.

5. Jianchun Z, Peixing F. Predicting the tensile strength of lyocell/ PET blended yarns. ITB International Textile Bulletin 1999;6(99):28-30.

6. Yang Z, Shen L. Effect of blended ratio on strength and elongation properties of outlast/ viscose blended yarn. Advanced Material Res 2011;332-334:407-11.

7. De SK, Mitra A. A comparative study on some mechanical properties of eri and cotton fabrics. Manmade Tex India 2005;48(11):430-34.

8. Lakhchaura P, Gahlot M. Physical properties of Oak tasar silk waste/acrylic blended fabrics. International Journal of Basic and Applied Agricultural Research 2018;16(1):81-84. 